\title{
A Treatment Technology for Optimizing the Stress State of Railway Tunnel Bottom Structure
}

\author{
Zili Han (D), ${ }^{1,2}$ Weibin Ma $\left(\mathbb{D},{ }^{1,2}\right.$ Jinfei Chai $\mathbb{D}^{1,},{ }^{1,2}$ Zhenyu Zhu, ${ }^{3}$ Chuannian Lin, ${ }^{4}$ \\ Zeli An $\mathbb{D}^{1,2}$ Chaofeng ${ }^{1,}{ }^{1,2}$ Xueliang $\mathrm{Xu}^{1,2}$ and Tianyuan $\mathrm{Xu}^{1,2}$ \\ ${ }^{1}$ Railway Engineering Research Institute, China Academy of Railway Sciences Corporation Limited, Beijing 100081, China \\ ${ }^{2}$ State Key Laboratory for Track Technology of High-Speed Railway, Beijing 100081, China \\ ${ }^{3}$ Beijing Railway Signal Corporation Limited, Beijing 100071, China \\ ${ }^{4}$ China Railway Economic and Planning Research Institute, Beijing 100038, China
}

Correspondence should be addressed to Weibin Ma; dwangfei@163.com and Jinfei Chai; chaijinfei@rails.cn

Received 20 May 2021; Accepted 1 July 2021; Published 21 July 2021

Academic Editor: Junfei Zhang

Copyright (c 2021 Zili Han et al. This is an open access article distributed under the Creative Commons Attribution License, which permits unrestricted use, distribution, and reproduction in any medium, provided the original work is properly cited.

\begin{abstract}
With the continuous increase of railway transportation volume, the aging problem of railway tunnel bottom structure is becoming more and more serious, which seriously threatens the safe operation of trains. Based on the cause analysis and field detection of the defects at the railway tunnel bottom structure, the "Anchor-Grouting-Drainage" treatment technology of the railway tunnel bottom structure is summarized. The research shows that (1) the technology is simple and can effectively repair the defects of railway tunnel bottom structure under the conditions of the narrow site, short time of maintenance skylight, strict requirements of track size variation, and no interference with the normal operation of the train, which has great significance and broad application prospect. (2) The drainage system of the existing railway tunnel bottom structure can be applied to the reconstruction of the railway tunnel bottom structure. The high-strength transverse diversion structure at the bottom of the tunnel has the advantages of strong bearing capacity, large drainage capacity, and corrosion resistance, which can provide a reference for the subsequent implementation of the reconstruction project at the railway tunnel bottom structure.
\end{abstract}

\section{Introduction}

In the railway tunnel disease treatment project, the basement subsidence, void, mud boiling, and other diseases are common tunnel disease types, which directly affect the bearing capacity and stability of the track structure, and will seriously affect the traffic safety of the railway transportation. However, due to the short time and discontinuity of the disease treatment project, the construction is difficult, and the early strength of the base reinforcement material is required to be high. Therefore, how to complete the bottom structure disease treatment construction in the limited maintenance skylight time without affecting the normal operation of the train is the key to the bottom structure disease treatment of railway tunnel [1-22].

\section{Project Overview}

According to the field survey results and the data provided by the tunnel management and maintenance unit, the diseases of railway tunnels are mainly concentrated in the bottom structure of the tunnel, mainly presenting as damage, cracking, and local void, as shown in Figures 1 and 2.

\section{Cause Analysis}

3.1. Damage and Void of Tunnel Bottom Structure. Ground penetrating radar (GPR) detection shows that the tunnel bottom is not dense and empty, which indicates that the low construction standard and long operation time of the tunnel are the main causes of tunnel bottom 


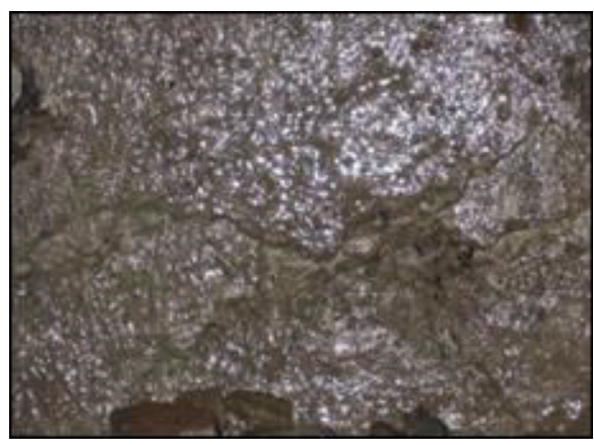

(a)

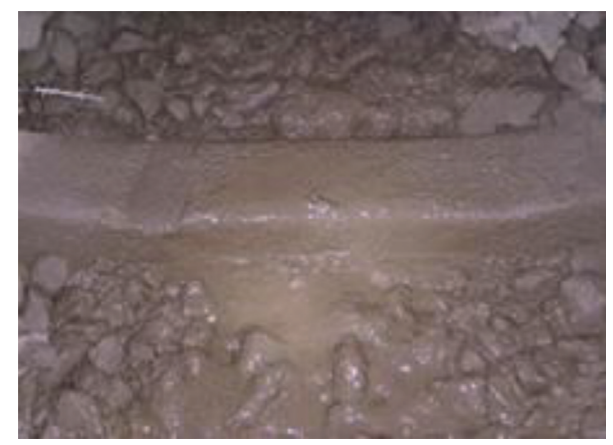

(b)

FIGURE 1: Crack and water leakage of tunnel bottom structure.

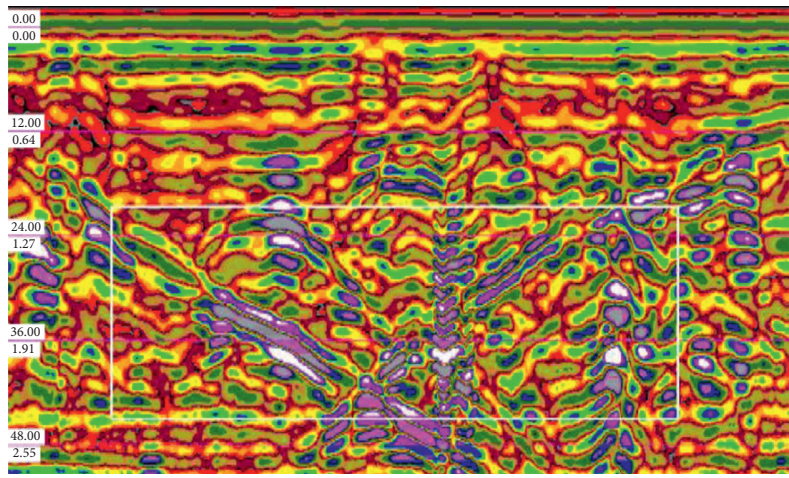

(a)

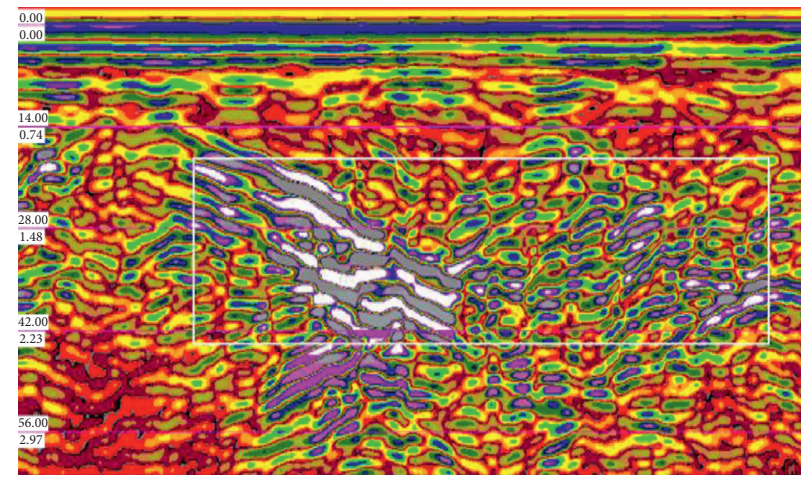

(b)

FIgURE 2: Radar detection maps of tunnel bottom structure fracture and water rich zone. (a) Fracture zone. (b) Water rich zone.

structure diseases. Secondly, the fatigue damage of the tunnel bottom structure under the train load for a long time and the pumping and grinding occur periodically under the train dynamic load. Finally, the bearing capacity of the bottom structure is greatly reduced, which is the main reason for the tunnel bottom structure disease in this section. Due to the poor drainage of the drainage ditch, the underground water within the tunnel bottom cannot be discharged in time, and the slurry formed by grinding with the fine particles at the tunnel bottom, spilling along the cracks of the damaged ditch structure, resulting in the tunnel bottom hanging disease, which is the direct cause of the tunnel bottom structure disease [3-6].

\subsection{Water Gushing from the Base and Water Accumulation in} the Central Ditch. The surface vegetation in the tunnel site is luxuriant and the root system is developed. Part of the atmospheric rainfall is accumulated and infiltrated into the rock stratum, which is the main water source of the water gushing from the roadbed; the fault fracture zone is developed near the tunnel disease area, and the surrounding rock at the tunnel bottom is broken and there are cracks, which provides a migration channel for the surface rainfall to flow out to the tunnel bottom; the tunnel bottom in the disease area cracks under the long-term circulation of heavy haul trains. It provides an outlet for the groundwater gushing out, and the ballast bed softens when the groundwater overflows into the ballast bed.

3.3. Necessity of Maintenance and Renovation. The damage, cracking, hanging, and other diseases of the tunnel bottom structure will greatly affect the stability of the line bottom structure, cause the geometric size change of the line, and then cause great hidden danger to the traffic safety. On the one hand, the disease of arch wall lining water leakage increases the degree of mud boiling disease of track bed, and at the same time, it is easy to form ice hanging and freezing damage in low temperature season, and the ice hanging disease may cause secondary diseases such as foreign body invasion and ballast bed ice and also cause great hidden danger to the traffic safety.

3.4. Scheme Comparison and Selection. In view of the current situation of railway tunnel diseases and the longterm large axle load, large traffic volume, high-density and heavy-duty transportation status, the overall treatment objectives of railway tunnel diseases are determined as follows: (1) strengthen the bottom structure of the tunnel and improve the bearing capacity of the structure; (2) improve the structural durability; (3) there is no hidden danger of driving safety during the implementation of the scheme. A 
total of three maintenance schemes have been developed, as shown in Table 1.

According to the analysis, the scientific applicability of the three schemes can meet the needs of maintenance and renovation; the first scheme has the lowest construction cost, but the tunnel bottom structure disease is easy to recur; the second scheme has the highest total cost, but it can eradicate the tunnel bottom structure disease; from the perspective of construction operability, the grouting water glass treatment scheme and the "Anchor-Grouting-Drainage" integrated comprehensive treatment scheme are both convenient for construction. Advantages: the machine is convenient, the construction process is simple, each process can be connected across the maintenance skylight, can be constructed within 2 hours of maintenance skylight time, and the process can be divided into parts. The construction process of the long-distance overhead line bottom replacement treatment scheme is complex, each process cannot be connected across the maintenance skylight, and it needs more than 4 hours of maintenance skylight time. Through comprehensive comparison and selection, the scientificity and economic rationality of Scheme III meet the requirements. Therefore, scheme III can be regarded as the recommended scheme.

\section{Technology Introduction}

The construction process of "Anchor-Grouting-Drainage" integrated comprehensive treatment technology for tunnel bottom structure mainly includes anchor bolt installation, reinforcement material pouring, track geometry dimension monitoring, vertical overflow hole construction of drainage ditch, transverse drainage hole construction of ballast bed, etc.

The construction process decomposition principle of "Anchor-Grouting-Drainage" integrated comprehensive treatment technology for tunnel bottom structure:

(1) When each construction project is decomposed into several processes, the operation time of each process shall not exceed 180 minutes given by the general process of tunnel construction blocking time plan; otherwise, further decomposition is required

(2) Each decomposed process must become a process that does not need continuous operation independently so as to prevent the influence of tunnel traffic safety and construction quality

\subsection{Hole Forming and Installation of Anchor Rod}

4.1.1. Overview. Design of anchoring and grouting of the tunnel bottom structure can be seen in Figure 3. In the process of anchor construction, it is planned to conduct parallel and flow construction with other construction organizations and increase the input of personnel, machinery, and materials to meet the construction needs.

The construction steps of the anchor rod are as follows:

Hole location fixing $\longrightarrow$ slag raking and pipe laying $\longrightarrow$ drilling rig in place $\longrightarrow$ machine position adjustment $\longrightarrow$ hole forming $\longrightarrow$ anchor rod installation $\longrightarrow$ reinforcement material pouring

\subsubsection{Construction Preparation}

(1) Technical Preparation. Before construction, the drawings should be read and the technical disclosure should be done well.

(2) Material Preparation. Anchor rod, expansion shell end, TK reinforcement material, PVC pipe.

(3) Surveying and Setting Out. The survey engineer shall set out the control points according to the drawings and determine the anchor rod position according to the site conditions.

\subsubsection{Construction Technology and Operation Steps of An- chor Rod}

(1) Measurement and Setting Out of Bolt Hole. According to the requirements of the design plan, the anchor hole position shall be accurately measured and set out on the track and marked with lime. The hole position error shall not exceed $\pm 30 \mathrm{~cm}$. The bolt spacing can be adjusted according to the actual situation. In case of a special difficult site, it shall be approved by the design unit. On the premise of meeting the bottom structure reinforcement effect, the hole location arrangement can be appropriately relaxed.

(2) Drilling Equipment. According to the thickness of tunnel bottom concrete, surrounding rock type, anchor hole diameter, anchor depth, and construction site conditions, the drilling equipment is comprehensively selected. The project plans to use a single pneumatic rock drill assisted by an electric hammer for anchor hole forming; hollow hexagonal drill rod is used for drill pipe; pipe following drilling technology is adopted in the section where the rock stratum is broken or soft and rich in water and easy to collapse, shrink and jam.

(3) Rig in Place. When the drilling rig is moved to the construction site, the machine position shall be adjusted carefully to ensure that the vertical and horizontal error of the anchor hole shall not exceed $\pm 50 \mathrm{~mm}$, the elevation error shall not exceed $\pm 100 \mathrm{~mm}$, and the drill pipe shall run down vertically.

(4) Drilling Method. Dry drilling is required for drilling, and water drilling is not allowed to be used to ensure that the construction of anchor rod will not deteriorate the engineering geological conditions of the rock mass at the base of the tunnel and the bond performance of the hole wall. The drilling speed shall be strictly controlled according to the performance of the drilling rig and the anchoring stratum so as to prevent the drilling hole from twisting and diameter changing, resulting in anchoring difficulties and other accidents. 
TABLE 1: Comparison of maintenance and renovation schemes.

\begin{tabular}{lcc}
\hline Category & Scheme 1 & Scheme 2 \\
\hline $\begin{array}{l}\text { Program } \\
\text { content }\end{array}$ & $\begin{array}{c}\text { Grouting cement water glass } \\
\text { treatment }[7]\end{array}$ & $\begin{array}{c}\text { Bottom changing of long-distance } \\
\text { overhead lines [8] }\end{array}$ \\
\hline
\end{tabular}

It can quickly block and repair the fracture, but the plugging effect is poor under the condition of flowing water;

The cement consolidation strength Scientific cannot meet the structural strength applicability requirements of the railway tunnel bottom structure. Water glass has a strong corrosion effect on the waterproof layer at the tunnel bottom, and the cracks and leakage water diseases are easy to recur.
It can completely solve the structural damage and water leakage of the ballastless track, but it needs to be constructed under the condition of sufficient time for single maintenance skylight time (4 hours-6 hours) and interval speed limit, which has a great impact on online transportation. The scheme is suitable for tunnel bottom structure damage, which affects traffic safety.
The construction process is complex, and each process cannot be connected across the maintenance skylight. The market demand for single maintenance skylight time is long, which needs more than 4 hours.
The machine is convenient, the construction process is simple, each process can construct across the

Construction operability maintenance skylight, the time of a single maintenance skylight is short, the construction can be carried out within 2 hours maintenance skylight time, and the process can be divided into parts.

\begin{tabular}{lccc}
\hline $\begin{array}{l}\text { Economic } \\
\text { rationality }\end{array}$ & Low & High & Moderate \\
\hline
\end{tabular}

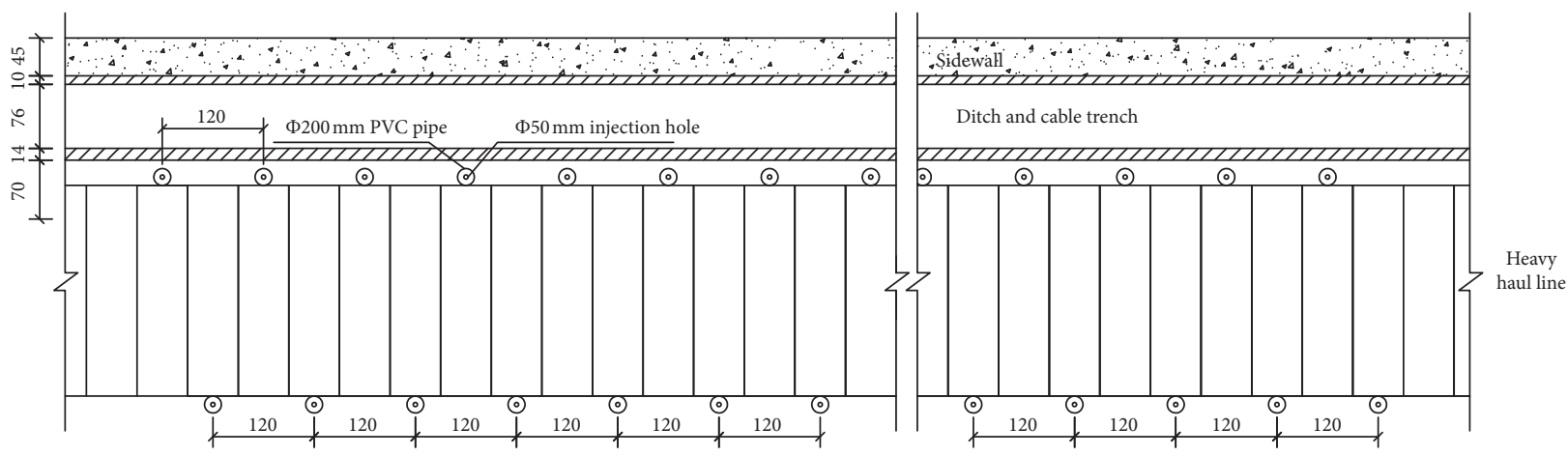

(a)

Figure 3: Continued. 


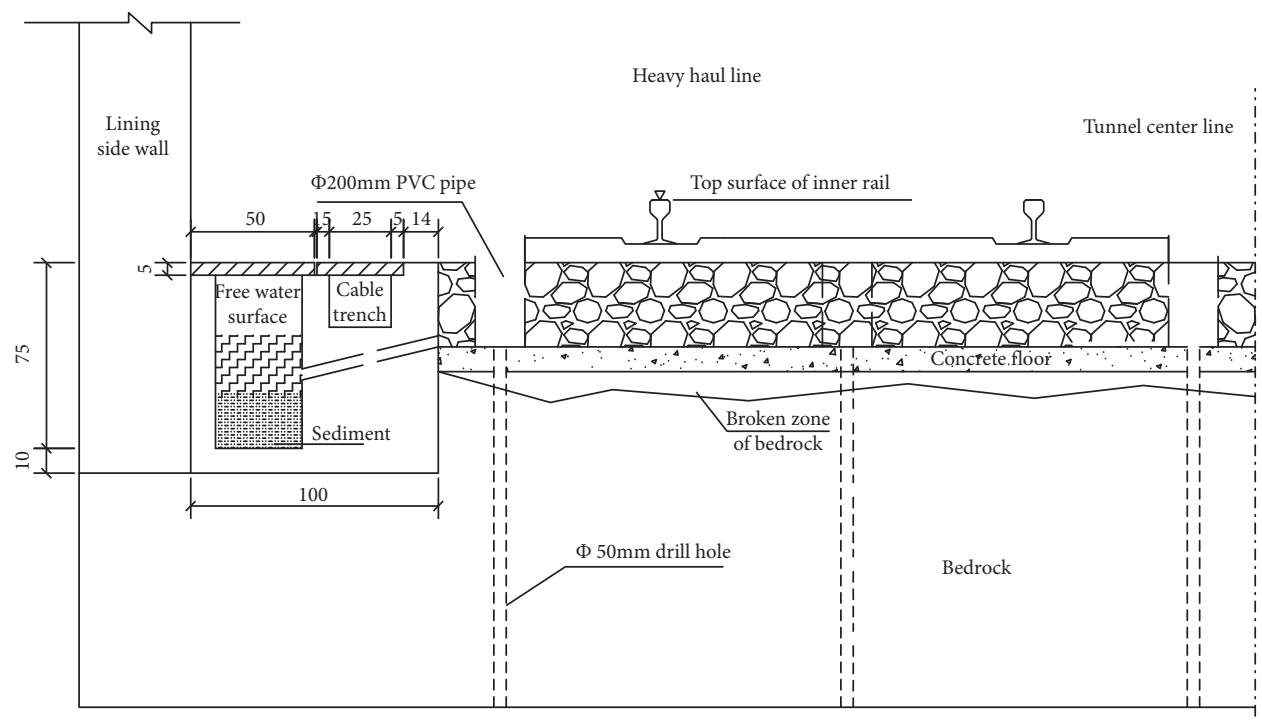

(b)

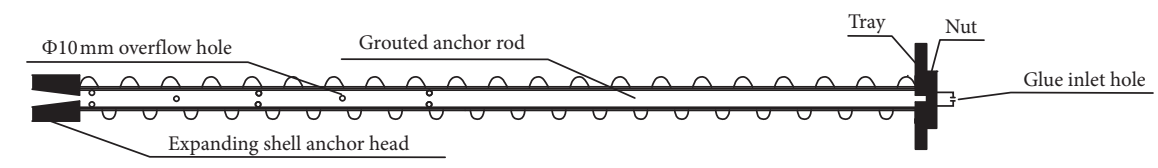

(c)

FIGURE 3: Design of anchoring and grouting of tunnel bottom structure. (a) Plan (b) Section. (c) Section of anchor pile.

(5) Drilling Process. During the drilling process, the field construction records shall be made for the formation changes of each hole, the drilling status (bit pressure, drilling rate), and some special conditions. In case of poor drillings, such as hole collapse and shrinkage, the drilling must be stopped immediately, and the wall consolidation grouting treatment (grouting pressure $0.1 \sim 0.2 \mathrm{kPa}$ ) should be carried out in time. After the initial setting of the grouting material, the hole cleaning and drilling should be carried out again.

(6) Hole Diameter and Depth. The hole diameter and depth shall not be less than the design value. In order to ensure the diameter of the bolt hole, the actual diameter of the drill bit should not be less than the designed diameter. In order to ensure the depth of the anchor hole, the actual drilling depth is required to be more than $0.2 \mathrm{~m}$ than the design depth.

(7) Bolt Hole Cleaning. When the drilling depth reaches the design depth, the drilling cannot be stopped immediately. The drilling should be stable for 1-2 minutes to prevent the bottom of the hole from pinching out and failing to reach the designed hole diameter. The borehole wall shall be free of sediment and mud water mixture and must be cleaned up. After the completion of drilling, high-pressure air (wind pressure $0.2 \sim 0.4 \mathrm{kPa}$ ) is used to remove the rock powder and water from the hole. Except for relatively hard and complete surrounding rock anchoring, high-pressure water flushing is not allowed. If there is confined water flowing out of the anchor hole, the anchor bolt and grouting can be carried out after the water pressure and water volume become smaller. If necessary, drainage holes should be set up at appropriate parts around the anchor hole.
(8) Bolt Hole Inspection. After the completion of anchor hole drilling, the next process can be carried out after passing the site inspection. The hole diameter and hole depth are generally checked by comparing the designed hole diameter, drill bit, and standard drill pipe. It is required that the drill bit can be pushed forward smoothly without impact or shaking during hole inspection. The inspection length of the drilling tool shall meet the design bolt hole depth, and the drilling withdrawal shall be smooth. There shall be no obvious splashing dust and water body during the inspection with the high-pressure wind.

(9) Bolt Installation. It is proposed to adopt the expanded shell prestressed anchor pile, which is composed of the expanded shell anchor head, anchor body, base plate, nut, and connecting sleeve. The main characteristics of the bolt are as follows:

(1) The operation is simple, and the conventional tensioning tools (such as torque wrench and anchor tension meter) can be used to apply prestress

(2) The construction equipment is simple, $2 \sim 3$ people can carry out the construction

(3) Through the hollow rod body, the reinforcement material is poured into realizing the consolidation of the bottom and the surrounding rock of the base

(4) The rock socketed end is provided with an expanding shell end, which can realize tension and firmly support the bedrock 
(10) Anchoring Grouting. Place the double material liquid glue injection machine on the reinforcement site, connect the grouting pipe and high-pressure gas source, start the grouting machine, and inject the slurry into the base to be reinforced through the anchor rod until the slurry overflows at the end of the anchor rod or the slurry overflows from the adjacent observation hole. After the completion of the multihole grouting, take down the grouting joint and clean the equipment.

4.2. TK Reinforcement Material Pouring. TK reinforcement material is used to reinforce the tunnel bottom structure. This material has the advantages of rapid hardening and high initial strength and has great advantages in the reinforcement of the upper lining of the tunnel or the base curing. The material construction adopts a special double slurry injection pump, and the main process flow is as follows:

Field material mixing experiment $\longrightarrow$ grouting pump assembly $\longrightarrow$ hose connection $\longrightarrow$ grouting pipe connection $\longrightarrow$ glue injection $\longrightarrow$ pipe $\quad$ replacement $\longrightarrow$ glue injection completion $\longrightarrow$ special cleaning agent cleaning

Note that before glue injection, the mixing effect must be determined to ensure the material quality. After using, the injection pump should be cleaned immediately to prevent blockage. The pipe replacement must be fast to prevent the grouting pipe from blocking.

\subsection{Add Drainage Structure under Rail}

4.3.1. Overview. High-strength transverse diversion structure at the bottom of the tunnel can be seen in Figure 4. The construction process of this project is planned to be parallel with other construction organizations and flow construction while increasing the input of personnel, machinery, and materials to meet the construction needs. The construction steps are as follows:

Sleeper displacement $\longrightarrow$ ballast raking $\longrightarrow$ transverse drainage hole setting $\longrightarrow$ horizontal drainage pipe placing $\longrightarrow$ drainage structure under track laying $\longrightarrow$ sleeper reset $\longrightarrow$ ballast backfilling and tamping $\longrightarrow$ line slope remeasurement

\subsubsection{Construction Preparation}

(1) Technical Preparation. Before construction, the drawings should be read carefully and the technical disclosure should be done well.

(2) Material Preparation. Blind drainage pipe, repair mortar, underflow structure, PVC, geotextile pipe, rubber corrugated plate.

(3) Surveying and Setting Out. The survey engineer shall set out the control points according to the drawings and determine the hole position according to the site conditions.

\subsubsection{Construction Technology and Operation Steps}

Step 1: sleeper displacement

The adjacent sleepers will be displaced to make clearance for the subsequent steps

Step 2: remove ballast

Remove and bag the ballast at the track pillow until it is exposed to the bottom surface, and place the bagged ballast properly

Step 3: horizontal drainage hole drilling

The air drill should be used to drill holes in the direction of the drainage ditch, with an aperture of about $6 \mathrm{~cm}$. The hole should be exposed at the side of the drainage ditch close to the track bed and $20 \mathrm{~cm}$ away from the bottom of the ditch.

Step 4: place the horizontal drainage pipe

The drainage pipe is put into the horizontal drainage hole, and the hole is wrapped with filter materials such as geotextile

Step 5: place the high-strength transverse diversion structure at the bottom of the tunnel

The high-strength transverse diversion structure at the bottom of the tunnel is placed under the wide sleeper

Step 6: sleeper reset

Reset the displaced sleeper

Step 7: ballast backfilling and tamping

The ballast shall be backfilled and tamped effectively

Step 8: line geometric dimension compounding

The track gauge is used for a linear compound of the disease treatment section

\subsection{Construction of Longitudinal Drainage Blind Pipe of Track Bed}

4.4.1. Overview. The design of the drainage system at the bottom of the tunnel can be seen in Figure 5. The project is planned to work in parallel with other construction organizations and increase the input of personnel, machinery, and materials to meet the construction needs. The main construction steps are as follows:

Excavation of trench by ballasting $\longrightarrow$ laying of blind drainage pipe $\longrightarrow$ laying of geotextile $\longrightarrow$ laying of corrugated rubber plate $\longrightarrow$ backfilling of ballast

\subsubsection{Construction Preparation}

(1) Technical Preparation. Before construction, the drawings should be read and the technical disclosure should be done well.

(2) Material Preparation. Drainage blind pipe, geotextile pipe, rubber corrugated plate. 


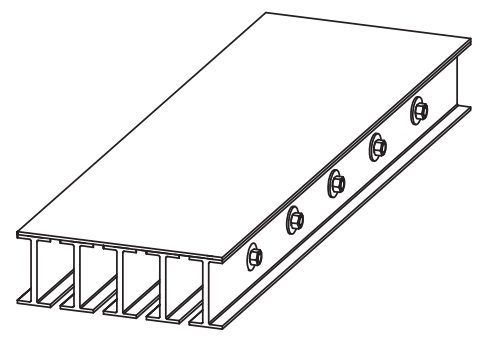

(a)

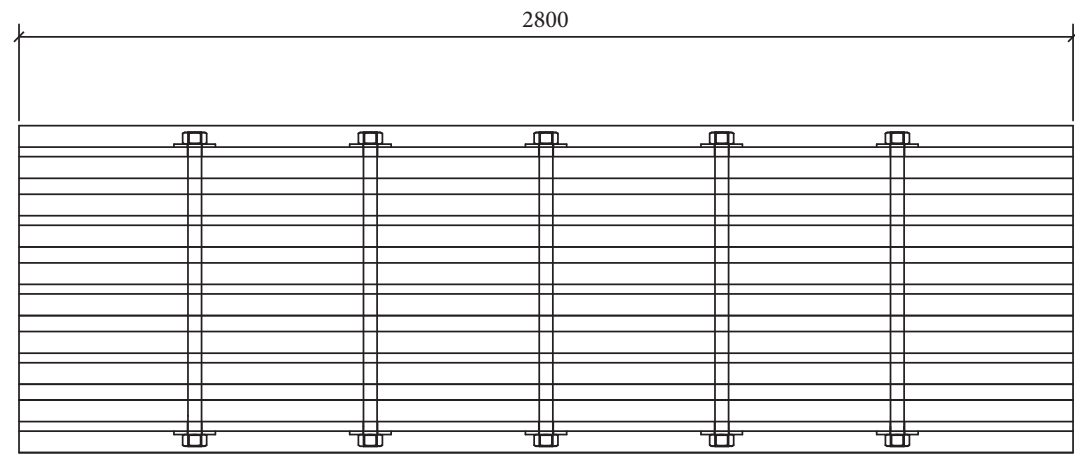

(b)

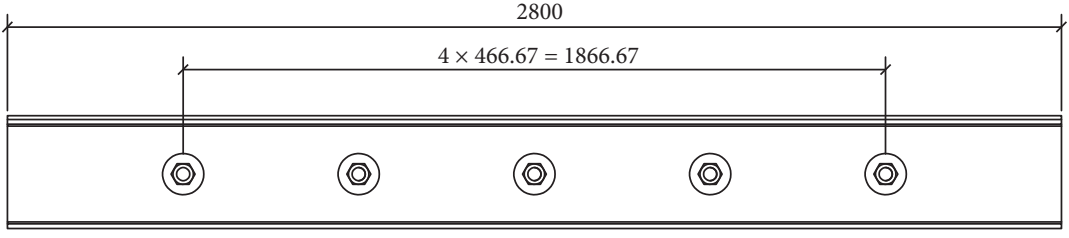

(c)

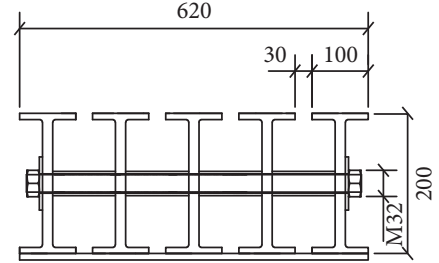

(d)

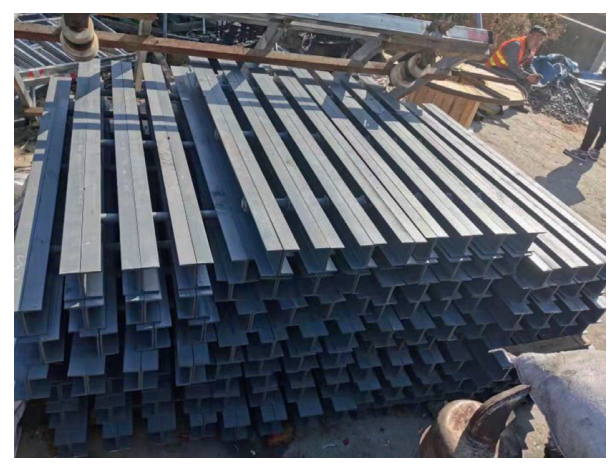

(e)

Figure 4: High-strength transverse diversion structure at the bottom of the tunnel. (a) 3D stereogram. (b) Top view. (c) Side view. (d) Section. (e) Physical picture.

(3) Surveying and Setting Out. The survey engineer shall set out the control points according to the drawings and determine the hole position according to the site conditions.

\subsubsection{Construction Technology and Operation Steps}

Step 1: ballast removal and trench excavation According to the design position, the two ends of sleepers shall be excavated along the line according to the design size to the top surface of the concrete bottom plate.
Step 2: install blind drainage pipe

The blind drainage pipe is installed in the trench. During the security, two blind pipes are placed side by side and laid continuously along the trench.

Step 3: geotextile laying

Use geotextile to protect the top surface of the blind drainage pipe laid to prevent coal dust from blocking the blind drainage pipe

Step 4: lay rubber corrugated plate 


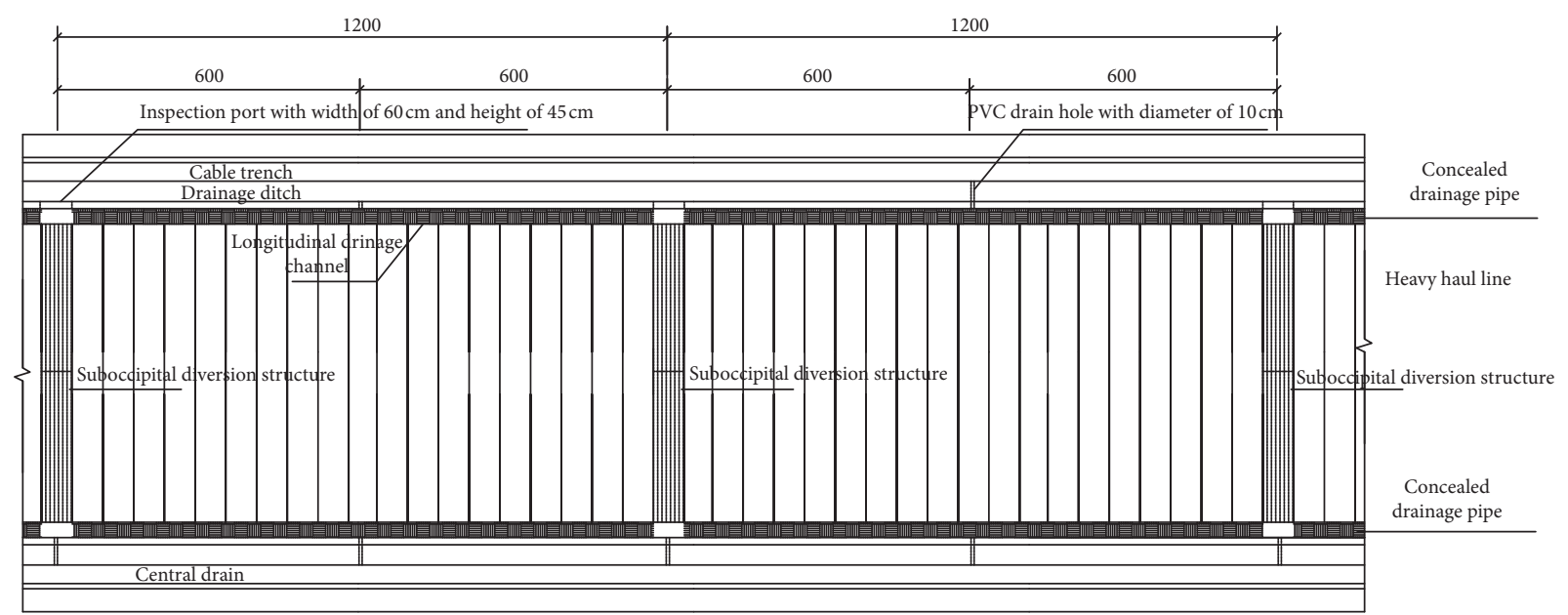

(a)

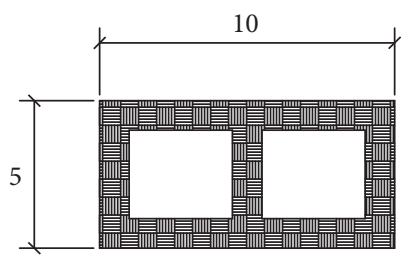

(b)

FIgURE 5: Design of drainage system at the bottom of tunnel. (a) Layout plan. (b) Cross section of longitudinal drainage pipe structure.

The rubber corrugated plate is laid on the top of the geotextile to prevent the ballast from squeezing the blind drainage pipe

Step 5: ballast backfilling

The corrugated sleeper is used to fill the ballast surface to the track surface

\subsection{Analysis of Key and Difficult Points in Construction}

4.5.1. Track Smoothness Control in Glue Injection Process. In the process of base glue injection, the track may be lifted under the action of glue injection pressure, which is not conducive to the smooth operation of the train after the line is opened. In the process of implementation, the track ruler and laser leveling instrument are used to monitor the track elevation change in the affected range during the glue injection process.

4.5.2. Reasonable Construction Organization Design within Effective Time. The maintenance skylight time of the railway is precious, and the construction period of disease treatment is relatively tight. Therefore, it is necessary to formulate a reasonable and effective construction organization design, which is the focus of this construction.

4.5.3. Construction of Transverse Drainage Hole of Track Bed. From the angle of controlling the direction of the side drainage ditch of the track bed, the drilling construction is the difficulty of this construction.

\subsection{Construction Impact Analysis}

(1) It is necessary to block the line during the construction and operate in the maintenance skylight time

(2) During the implementation of the project, construction protection and preliminary preparation should be done to ensure construction safety

(3) In the reinforcement treatment of tunnel bottom, the risk prevention and control of drilling stuck emergency disposal should be done well

\section{Stress Analysis before and after the Treatment Technology}

5.1. Axle Load Conversion Method. Under the dynamic load of a freight train, the surface of track bed mainly bears the load of the sleeper. Taking the sleeper as the medium of load transfer, it is assumed that a load of heavy haul trains has no attenuation in the process of sleeper transfer. Based on the stress mode of the ballast bed structure of the freight railway tunnel under the action of the sleeper, the static axle load/ wheel load is converted into the dynamic axle load/wheel load according to the train speed, and then the dynamic load added value threshold caused by the train is calculated by combining with the contact area of the sleeper bottom, as shown in the following equation:

$$
\sigma=\frac{P \cdot(1+\alpha v)}{B L}
$$

where $\sigma$ is the stress, $\mathrm{kPa}$; $P$ is the static axle load, $\mathrm{kN} ; \alpha$ is the dynamic impact coefficient, also known as the speed 
influence coefficient, which is 0.004 for heavy load railway; $V$ is the driving speed, $\mathrm{km} / \mathrm{h} ; \mathrm{B}$ is the average width of sleeper bottom; $L$ is the sleeper length.

5.2. Computing Analysis. According to the original design size, $120 \mathrm{~cm}$ thickness (the shape is simple wave shape within $5 \mathrm{~cm}$ ), $5 \mathrm{~cm}$ void layer, $10 \mathrm{~cm}$ void layer, and $15 \mathrm{~cm}$ void layer of tunnel bottom structure, the safety of single track railway tunnel bottom structure under $25 t$ axle load is simulated, respectively.

5.2.1. Original Design Size. The first principal stress of the tunnel bottom structure is $1.36 \mathrm{MPa}$ (see Figures 6 and 7), which is less than 1.7 MPa of the tensile strength limit of C20 concrete, meeting the safety requirements of the tunnel bottom structure.

5.2.2. The Thickness of Tunnel Bottom is $120 \mathrm{~cm}$. The first principal stress of the tunnel bottom structure is $2.51 \mathrm{MPa}$ (see Figures 8 and 9), which has exceeded the ultimate tensile strength of C20 concrete by $1.7 \mathrm{MPa}$, not meeting the safety requirements of the tunnel bottom structure.

5.2.3. $5 \mathrm{~cm}$ Void Layer. Before the "Anchor-GroutingDrainage" treatment, the first principal stress of tunnel substructure is $2.42 \mathrm{MPa}$ (see Figures 10 and 11), which has exceeded the tensile strength limit of C20 concrete by 1.7 MPa, and the maximum principal stress is on the cushion surface, not meeting the safety requirements.

After the "Anchor-Grouting-Drainage" treatment, the first principal stress of tunnel bottom structure is 1.66 $\mathrm{MPa}$ (see Figure 12), which is within the tensile strength limit of C20 concrete by $1.7 \mathrm{MPa}$, meeting the safety requirements.

5.2.4. $10 \mathrm{~cm}$ Void Layer. Before the "Anchor-GroutingDrainage" treatment, the first principal stress of tunnel substructure is $2.52 \mathrm{MPa}$ (see Figures 13 and 14), which has exceeded the tensile strength limit of C20 concrete by 1.7 $\mathrm{MPa}$, and the maximum principal stress is on the cushion surface, not meeting the safety requirements.

After the "Anchor-Grouting-Drainage" treatment, the first principal stress of tunnel bottom structure is 1.69 $\mathrm{MPa}$ (see Figure 15), which is within the tensile strength limit of C20 concrete by $1.7 \mathrm{MPa}$, meeting the safety requirements.

5.2.5. $15 \mathrm{~cm}$ Void Layer. Before the "Anchor-GroutingDrainage" treatment, the first principal stress of tunnel substructure is $2.64 \mathrm{MPa}$ (see Figures 16 and 17), which has exceeded the tensile strength limit of C20 concrete by 1.7 MPa, and the maximum principal stress is on the cushion surface, not meeting the safety requirements.

After the "Anchor-Grouting-Drainage" treatment, the first principal stress of tunnel bottom structure is $1.73 \mathrm{MPa}$

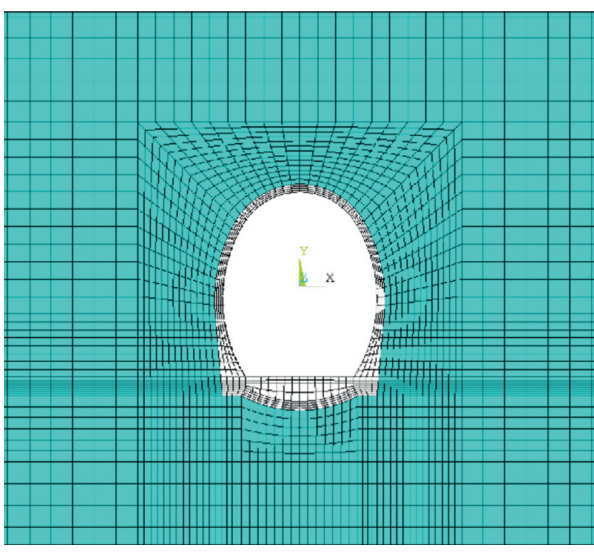

Figure 6: Computational model.

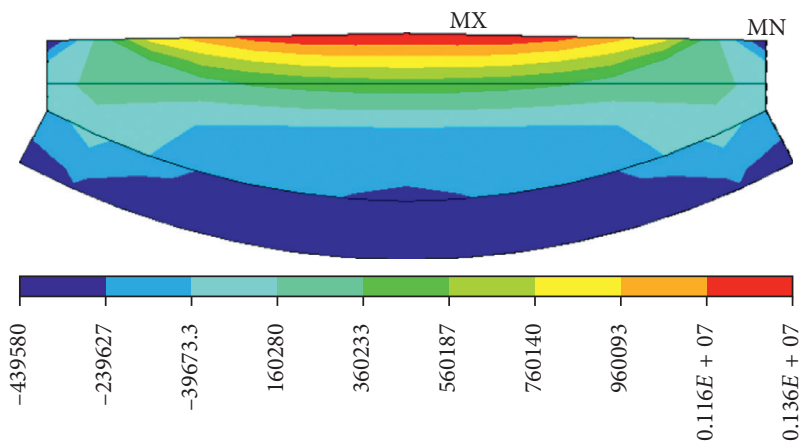

FIGURE 7: First principal stress of tunnel substructure $(\mathrm{Pa})$.

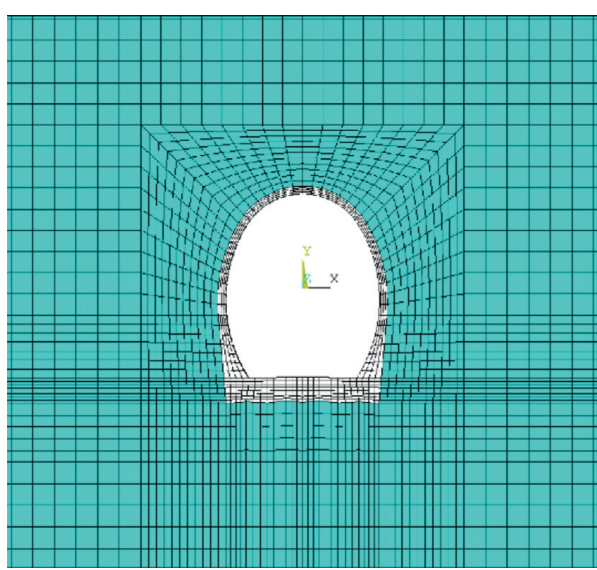

Figure 8: Computational model.

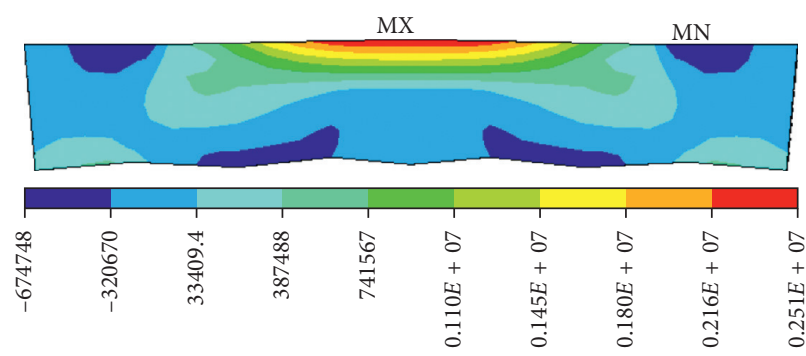

Figure 9: First principal stress of tunnel substructure (Pa). 


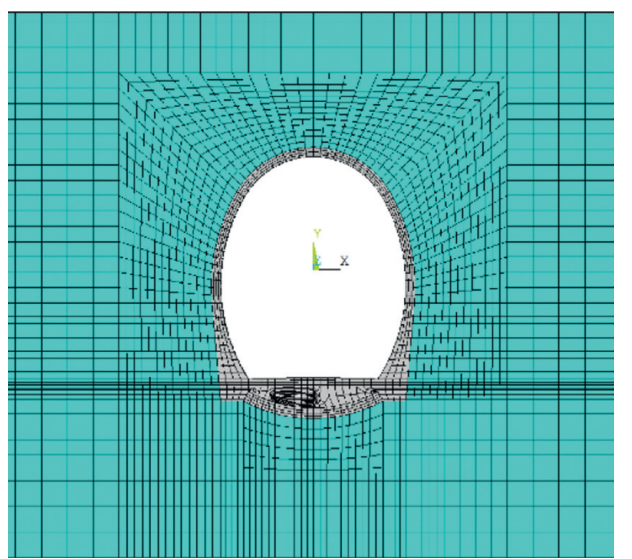

(a)

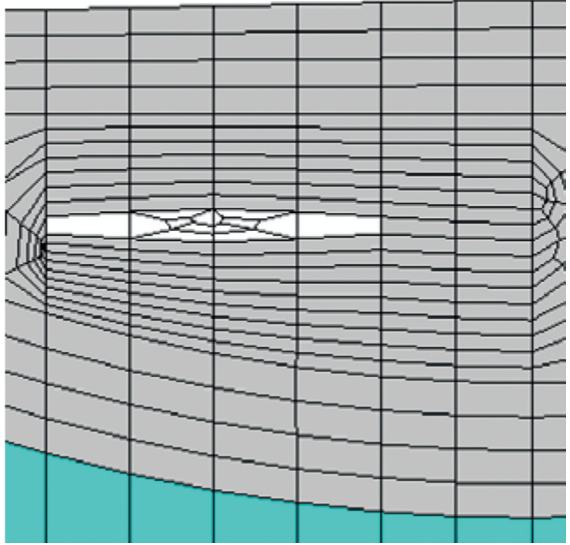

(b)

Figure 10: Computational model.

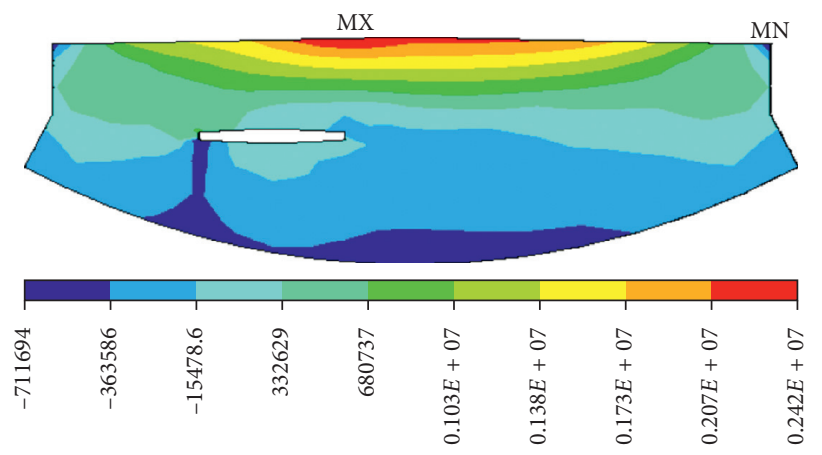

Figure 11: First principal stress of tunnel substructure $(\mathrm{Pa})$ before the treatment.

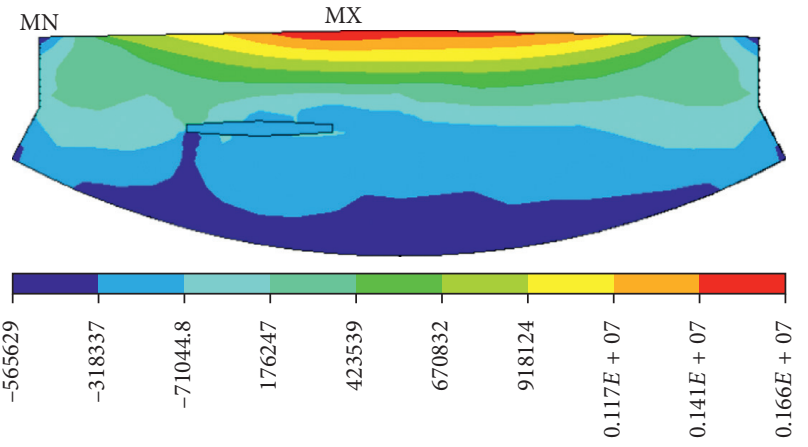

FIGURE 12: First principal stress of tunnel substructure $(\mathrm{Pa})$ after the treatment.

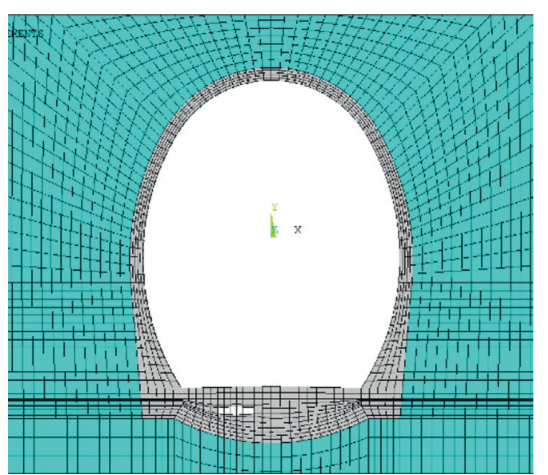

(a)

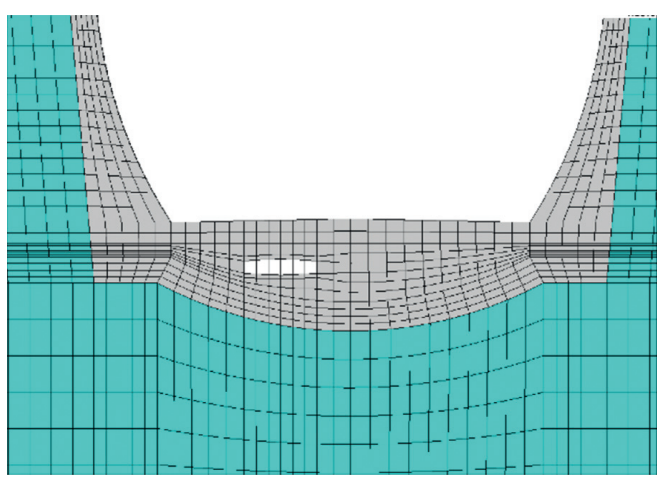

(b)

Figure 13: Computational model. 


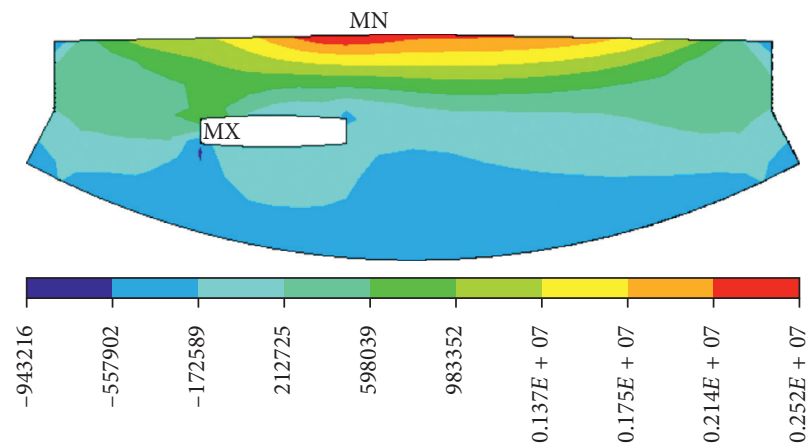

FIGURE 14: First principal stress of tunnel substructure (Pa) before the treatment.

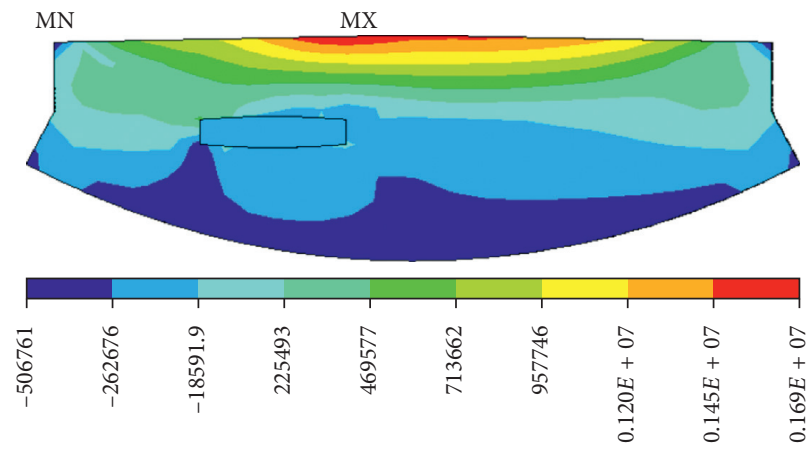

Figure 15: First principal stress of tunnel substructure $(\mathrm{Pa})$ after the treatment.

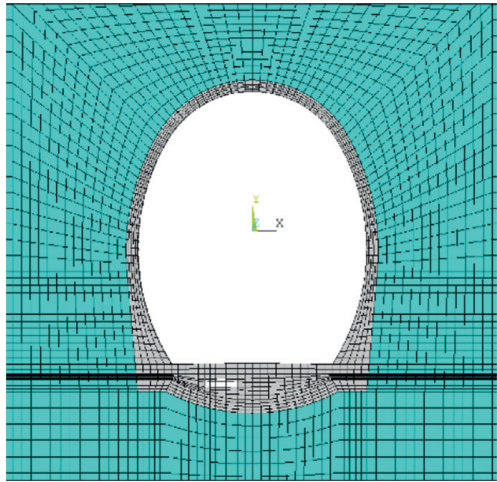

(a)

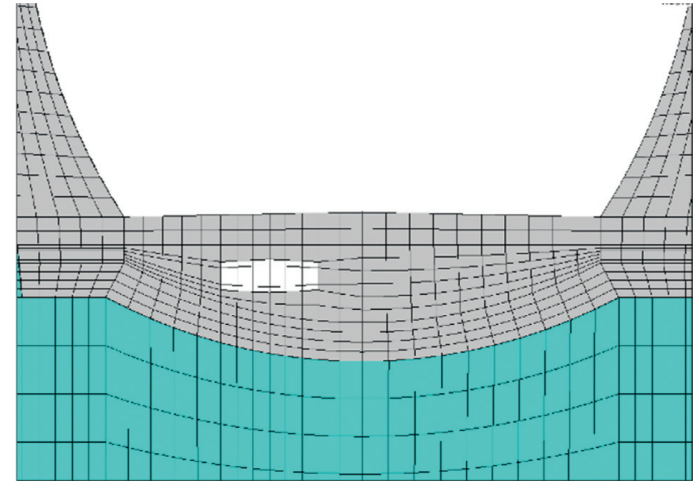

(b)

FIgURE 16: Computational model.

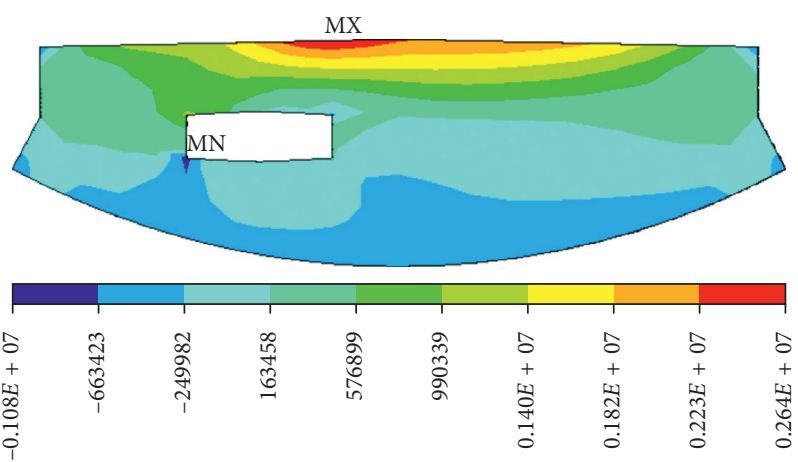

FIgURE 17: First principal stress of tunnel substructure $(\mathrm{Pa})$ before the treatment. 


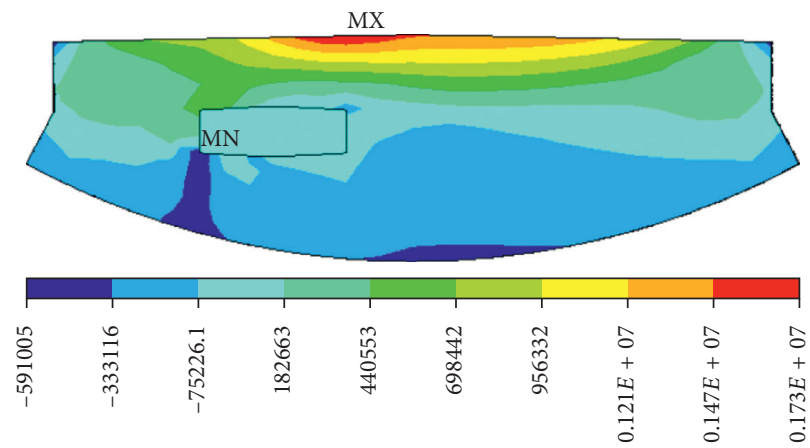

FIGURE 18: First principal stress of tunnel substructure (Pa) after the treatment.

(see Figure 18), which is within the tensile strength limit of C20 concrete by $1.7 \mathrm{MPa}$, basically meeting the safety requirements.

\section{Conclusion}

(1) The technology is simple and can effectively repair the defects of railway tunnel bottom structure under the conditions of the narrow site, short time of maintenance skylight, strict requirements of track size variation, and no interference with the normal operation of the train, which has great significance and broad application prospect.

(2) The drainage system of the existing railway tunnel bottom can be applied to the bottom structure renovation of a railway tunnel. The high-strength transverse diversion structure at the bottom of the tunnel has the advantages of strong bearing capacity, high drainage capacity and corrosion resistance, which can provide a reference for the subsequent implementation of the reconstruction project of the bottom structure of the railway tunnel.

\section{Data Availability}

The data used to support the findings of this study are available within the article.

\section{Conflicts of Interest}

The authors declare that there are no conflicts of interest regarding the publication of this paper.

\section{Acknowledgments}

The authors would like to thank the support of the Research Project of China Academy of Railway Sciences Corporation Limited (No. 2020YJ089). They also thank Dr. Yan Du from Beijing University of Science and Technology for his support to the numerical simulation in this paper.

\section{References}

[1] J. Lai, K. Wang, J. Qiu, F. Niu, J. Wang, and J. Chen, "Vibration response characteristics of the cross tunnel structure,"
Shock and Vibration, vol. 2016, Article ID 9524206, 16 pages, 2016.

[2] W. Garden and H. G. Stuit, "Modelling of soil vibrations from railway tunnels," Journal of Sound and Vibration, vol. 267, no. 1, pp. 605-619, 2003.

[3] A. V. Metrikine, A. C. W. M. Vrouwenvelder, Y. Q. Liu, and W. B. Ma, "Surface ground vibration due to a moving train in a tunnel: two-dimensional model," Journal of Sound and Vibration, vol. 234, no. 1, pp. 43-66, 2000.

[4] T. Balendra, C. G. Koh, and Y. C. Ho, "Dynamic response of buildings due to trains in underground tunnels," Earthquake Engineering \& Structural Dynamics, vol. 20, no. 3, pp. 275291, 1991.

[5] G. Degrande, M. Schevenelsa, and P. Chatterjeea, "Vibrations due to a test train at variable speeds in a deep bored tunnel embedded in London clay," Journal of Sound and Vibration, vol. 293, no. 1, pp. 626-644, 2006.

[6] Y. B. Yang and H. H. Hung, "Soil vibrations caused by underground moving trains," Journal of Geotechnical and Geoenviromental Engineering, vol. 134, no. 1, pp. 1633-1644, 2008.

[7] S. Wu, Z. Wu, and C. Zhang, "Rock burst prediction probability model based on case analysis," Tunnelling and Underground Space Technology, vol. 93, Article ID 103069, 2019.

[8] S. Wu, L. Han, Z. Cheng, X. Zhang, and H. Cheng, "Study on the limit equilibrium slice method considering characteristics of inter-slice normal forces distribution: the improved Spencer method," Environmental Earth Sciences, vol. 78, no. 20 , p. $611,2019$.

[9] S. Wu, S. Zhang, C. Guo, and L. Xiong, "A generalized nonlinear failure criterion for frictional materials," Acta Geotechnica, vol. 12, no. 6, pp. 1353-1371, 2017.

[10] $\mathrm{S}$. Wu, H. Wu, and J. Kemeny, "Three-dimensional discrete element method simulation of core disking," Acta Geophysica, vol. 66, no. 3, pp. 267-282, 2018.

[11] W. B. Ma, J. F. Chai, Z. L. Han et al., "Research on design parameters and fatigue life of tunnel bottom structure of single-track ballasted heavy-haul railway tunnel with 40-ton axle load," Mathematical Problems in Engineering, vol. 2020, Article ID 3181480, 9 pages, 2020.

[12] Z. Tao, C. Zhu, M. He, and M. Karakus, “A physical modelingbased study on the control mechanisms of Negative Poisson's ratio anchor cable on the stratified toppling deformation of anti-inclined slopes," International Journal of Rock Mechanics and Mining Sciences, vol. 138, Article ID 104632, 2021.

[13] C. Zhu, M. He, M. Karakus, X. Zhang, and Z. Tao, "Numerical simulations of the failure process of anaclinal slope physical model and control mechanism of negative Poisson's ratio 
cable," Bulletin of Engineering Geology and the Environment, vol. 80, no. 4, pp. 3365-3380, 2021.

[14] C. W. Fei, H. T. Liu, Z. Z. Zhu, L. An, S. Li, and C. Lu, "Wholeprocess design and experimental validation of landing gear lower drag stay with global/local linked driven optimization strategy," Chinese Journal of Aeronautics, vol. 34, no. 1, 2020.

[15] C. W. Fei, H. T. Liu, S. L. Li, H. Li, L. Q. An, and C. Lu, "Dynamic parametric modeling-based model updating strategy of aeroengine casings," Chinese Journal of Aeronautics, vol. 2021, no. 4, 2021.

[16] C. Fei, H. Liu, R. Patricia Liem, Y. Choy, and L. Han, "Hierarchical model updating strategy of complex assembled structures with uncorrelated dynamic modes," Chinese Journal of Aeronautics, vol. 2021, no. 4, 2021.

[17] C. W. Fei, T. Y. Yosef, D. G. Linzell, and J. D. Rasmussen, "Computational modeling and dynamic response of highway bridge columns subjected to combined vehicle collision and air blast," Engineering Failure Analysis, vol. 125, Article ID 105389, 2021.

[18] L. Han, C. Chen, T. Guo et al., "Probability-based service safety life prediction approach of raw and treated turbine blades regarding combined cycle fatigue," Aerospace Science and Technology, vol. 110, Article ID 106513, 2021.

[19] L. Han, Y. B. Wang, Y. Zhang, C. Lu, C. Fei, and Y. Zhao, "Competitive cracking behavior and microscopic mechanism of Ni-based superalloy blade respecting accelerated CCF failure," International Journal of Fatigue, vol. 150, Article ID 106306, 2021.

[20] Y. B. Niu, Research on Disease Mechanism and Treatment Technology of Railway Tunnel in, China Academy of Railway Sciences, Beijing, China, 2013.

[21] Y. Hua, Research on the Influence of Surrounding Rock Deterioration at the Bottom of Railway Tunnel in on the Stress of Tunnel Structure, Southwest Jiaotong University, Chengdu, China, 2018.

[22] J. F. Chai, "Research on m rock failure mechanism based on moment tensor theory," Mathematical Problems in Engineering, vol. 2020, Article ID 6816934, 17 pages, 2020. 